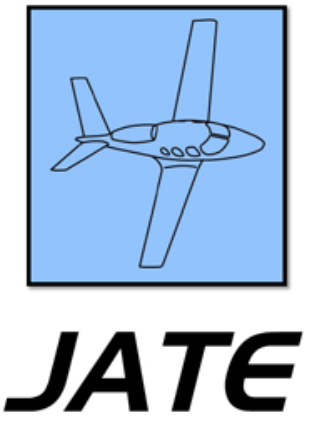

Journal of Aviation Technology and Engineering 5:1 (2015) 33-43

\title{
Marbles: The Application of Input-Output Concepts to Safety Management Systems
}

\author{
Tim Brady, Alan Stolzer, Anthony Brickhouse, Antonio Cortés, Dan McCune, \\ Jayathi Raghavan, and David Freiwald
}

(Embry-Riddle Aeronautical University)

\begin{abstract}
The goal of this research was to apply the economic concept titled Input-Output Analysis to an aviation safety concept titled Safety Management Systems (SMS). Input-Output (IO) is based upon the interrelationships of various components of an economic system and what happens to the system when one or more of those components changes. Since SMS is, by definition, a system with definable components, the research sought to determine if the interrelationships between those components could be determined and quantified. The term "marbles" was used to describe the
\end{abstract}

\begin{abstract}
About the Authors
Tim Brady, PhD Professor, Embry-Riddle Aeronautical University, holds a PhD in Higher Education Administration, an Airline Transport Pilot Certificate, and is a former military pilot and navigator. Brady's research interests include aviation history and aviation safety. Correspondence concerning this article should be sent to bradyt@erau.edu.
\end{abstract}

Alan Stolzer, PhD Professor, Embry Riddle Aeronautical University, holds a PhD in Quality Systems, an Airline Transport Pilot Certificate, and an A\&P mechanic certificate. Stolzer's research interests include Safety Management Systems and aviation safety programs.

Anthony Brickhouse, Embry-Riddle Aeronautical University, associate professor of aerospace and occupational safety, holds a BS in Aerospace Engineering and an MS in Aeronautical Science, and is an air safety investigator. Brickhouse's research interests include aviation safety and accident investigation.

Antonio Cortés, associate professor and chair of Applied Aviation Sciences at Embry-Riddle Aeronautical University, holds a PhD in business administration, an Airline Transport Pilot Certificate, and is a former military aviator, airline pilot, and government air safety investigator. Cortés' research interests include aviation hazard analysis and suborbital space flight.

Dan McCune, associate vice president for safety at Embry-Riddle Aeronautical University, holds a BS in human resource management an Airline Transport Pilot Certificate, and is a former US Army pilot flying fixed wing and helicopters. McCune has extensive safety training as a certified air safety investigator, and specializes in safety culture development and safety management system enhancement.

Jayathi Raghavan, PhD professor, Embry-Riddle Aeronautical University, holds a PhD in mathematics and an MS in computer science. Raghavan's research interests include numerical methods, computational mathematics and mathematics education.

David Freiwald, $\mathrm{PhD}$ assistant professor, Embry Riddle Aeronautical University, holds a PhD in aviation, an Airline Transport Pilot Certificate, and is a former airline pilot. Freiwald's research interests include investigation of safety cultures within aviation organizations. 
activities that led to the IO-SMS matrix. Marbles was used as a metaphor for quantifying interrelationships. A team of SMS experts was assembled to collectively determine the interrelationships among the four components of SMS. Next the team determined the relative values of the elements and processes inside each component. (There are 24 discrete items-elements and processes—in SMS.) Once these values were determined and placed into a $24 \times 24$ matrix, IO matrix mathematics was applied to produce the IO-SMS Matrix. The SMS matrix that resulted from this experiment may be a powerful management tool that can determine the impact of any numerical input, such as an SMS survey, on the total system. It can also be used to perform "what if" analysis by changing the value of one element or process within the SMS. The weakness of the IO-SMS matrix is that it is highly sensitive to the original input data that define the interrelationships among the components.

Keywords: $\quad$ safety management systems, SMS Input-Output Analysis, IO, assessing SMS, SMS evaluation

\section{Introduction}

People sometimes exist in the silo of things that interest them and perhaps are self-shielded from ideas outside of their own framework. In the same vein, researchers tend to use methods for exploring problems that are within the framework of their discipline, but occasionally, an event occurs that compels one to re-examine the wisdom of that practice. Recently, a student in a $\mathrm{PhD}$ in Aviation program, who is both an aviation educator and economist, wished to determine the effects of aviation on the economy of Florida using a process called Input-Output (IO) analysis. While IO is often used in economics research, it is rarely used in other domains. Since the premise of IO is based on the idea that the phenomenon under study is a system, it was proposed to apply IO to a system in the field of aviation-safety management systems (SMS) was identified as the appropriate subject. This paper presents the results of an experiment where SMS experts used IO concepts to explore safety management systems interdependencies by using marbles as a metaphor for quantifying interrelationships.

\section{Input-Output Analysis}

"Input-Output analysis is a method of systematically quantifying the mutual interrelationships among the various sectors of complex economic system" (Leontief, 1986, p. 19). "The fundamental information used in input-output analysis concerns the flows of products from each industrial sector, considered as a producer to each of the others, considered to be consumers" (Miller \& Blair, 2009, p. 2). This is illustrated by referring to the matrix shown in Table 1.
As Kelly George (2014) states in her dissertation:

The IO matrix also allows users to discover how a change in final demand in as little as one industry can impact each other industry's output. Economic interdependencies can be described through the industry product flow accounts and relationships; furthermore industry interrelationships can be determined by analyzing an economy's IO matrix (Leontief, 1949). In short, the IO model can be referred to as an impact model, enabling the researcher to trace specified changes in industry activities as a result of a change in final demand (p. 19). And:

IO analysis is accepted as a reliable method for conducting descriptive analyses and forecasting and assessing policy impact scenarios (Dietzenbacher \& Lahr, 2008), inter alia. An IO model's usefulness is in the ability to estimate the indirect impacts of a final demand change by detailing the interdependency of the economy's industry. Isard et al. (1998b) maintain that because of IO's interdependency of industry capabilities, it is an indispensable part of economic impact research. IO models produce a multiplier index that is useful in measuring the total impact of a change in final demand on inter-industry demand that can be used for forecasting (George, 2015, p. 24).

\section{Safety Management Systems}

SMS is becoming the standard worldwide for managing aviation safety. According to the International Civil Aviation

Table 1

Leontief's classic Input-Output matrix.

\begin{tabular}{lcccc}
\hline $\begin{array}{l}\text { Into } \\
\text { from }\end{array}$ & $\begin{array}{c}\text { Sector 1 } \\
\text { Agriculture }\end{array}$ & $\begin{array}{c}\text { Sector 2 } \\
\text { Manufacturing }\end{array}$ & $\begin{array}{c}\text { Sector 3 } \\
\text { Households }\end{array}$ \\
\hline Agriculture & 25 & 20 & 55 & 100 bushels of wheat \\
Manufacturing & 14 & 6 & 30 & 50 yards of cloth \\
Households & 80 & 180 & 40 & 300 man-years of labor \\
\hline
\end{tabular}

Note. Leontief's classic Input-Output matrix. In this table, row two, for example, indicates the contributions of Agriculture, Manufacturing, and Households to produce 100 bushels of wheat. Agriculture by itself cannot produce wheat; rather the Agriculture sector is dependent on both of the other two sectors to produce the output.

Adapted from Leontief, W. (1986), p. 20. 
Organization, SMS is a "systematic approach to managing safety, including the necessary organizational structures, accountabilities, policies and procedures" (ICAO, 2013, p. xii). While SMS has existed in other industries for decades, only recently has ICAO mandated that its member states (i.e., 189 member countries) develop and implement an SMS. The Federal Aviation Administration (FAA) very recently published its SMS rule for air carriers operating under 14CFR121 (scheduled air carriers, such as Delta, American, or Southwest) (Safety Management, 2015).

Some of the key characteristics of SMS that are reflected in the framework developed by ICAO are that it is: a dynamic risk management system; it is based on quality management system (QMS) principles; it exists in a structure scaled appropriately to the operational risk; and it is applied in a safety culture environment (Stolzer, Halford, \& Goglia, 2015). Put simply, SMS is a data-driven system to manage risk and should be considered a fundamental business process. These characteristics can be found in the SMS Framework developed by ICAO, which includes four components, 12 elements, and 17 processes. A listing of these is shown in A1-1 (FAA, 2015, Appendix 1, p. 1-2).

\section{Research Question}

Given the success of the IO model in the field of economics, it seemed likely that the IO concepts could be applied to other subjects claiming to be a system; hence the question: Would IO be useful in assessing SMS? It was this question that led a team of researchers to begin exploring a means to determine if an economic concept, IO, could be applied to an aviation safety concept, SMS.

\section{Methods}

\section{Applying IO to SMS}

It was first necessary to determine the relative importance of the four major components of SMS, (1) Safety Policy and Objectives (SPO), (2) Safety Risk Management (SRM), (3) Safety Assurance (SA), and (4) Safety Promotion (SP), to the whole.

Marbles. The team leader asked five volunteer members, each of whom was considered an expert in SMS, to participate in the experiment. The team was composed of four $\mathrm{PhDs}$ and one $\mathrm{PhD}(\mathrm{ABD})$, each of whom teaches SMS in a university environment, and the University Safety Officer who is an SMS practitioner. The team leader provided the following information by email to each of the five members: ${ }^{1}$

I spoke to you several weeks ago about trying to use an economic process called Input-Output to see if it had

\footnotetext{
${ }^{1}$ For the purpose of clarification, all email correspondence will be shown in italics.
}

Table 2

SMS components, elements, and processes.

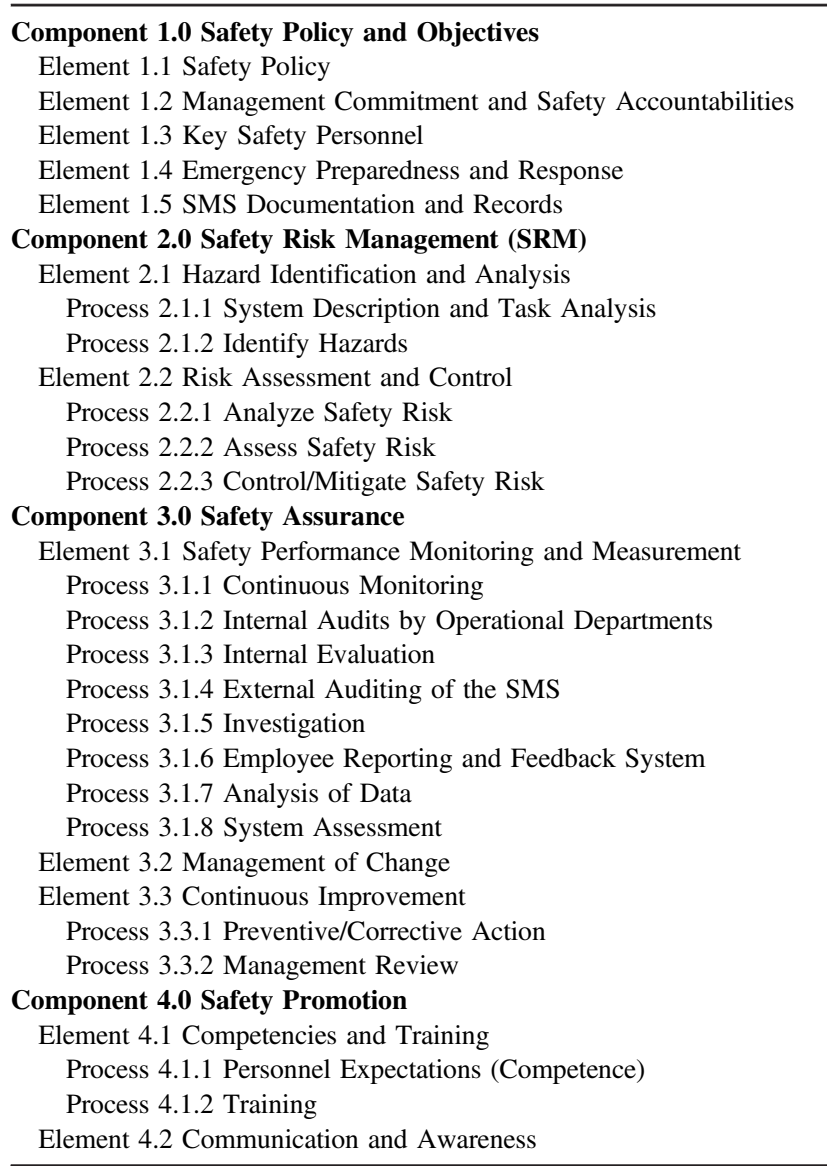

any applicability to the Safety Management System (SMS). What I'd like to do is to make a beginning stab as to the relative importance of each of the four major components of the SMS.

So visualize the four components as four baskets. I'm going to give you 100 marbles for each component (basket). I would like you to place the marbles in the baskets based on your judgment of the relative worth of each of the components to the whole system. It is not necessary to place all 100 marbles in any basket. For example, if you think that Component 2. Safety Risk Management is worth 50 marbles then that's what you would virtually place in that basket. You can't use the 50 marbles left over from that basket to place in any other basket. Clear as mud?

So you should end up with something like this as an example.

1. $S P O-80$

2. $S R M-50$

3. $S A-100$

4. $S P-30$

Okay, give it a shot. How would you place the marbles? There is no right or wrong answer. 
Table 3

The relative importance of each of the AMS components.

\begin{tabular}{|c|c|c|c|c|c|c|c|}
\hline & & Member 1 & Member 2 & Member 3 & Member 4 & Member 5 & Marbles ${ }^{1}$ \\
\hline & Raw Numbers & & & & & & \\
\hline 1 & Safety Policy and Objectives & 85 & 80 & 95 & 100 & 80 & \\
\hline 2 & Safety Risk Management & 65 & 85 & 100 & 80 & 40 & \\
\hline 3 & Safety Assurance & 55 & 95 & 85 & 75 & 30 & \\
\hline \multirow[t]{3}{*}{4} & Safety Promotion & 45 & 90 & 60 & 85 & 100 & \\
\hline & Total & 250 & 350 & 340 & 340 & 250 & \\
\hline & Percentages & & & & & & \\
\hline 1 & Safety Policy and Objectives & 0.340 & 0.229 & 0.279 & 0.294 & 0.320 & 0.292 \\
\hline 2 & Safety Risk Management & 0.260 & 0.243 & 0.294 & 0.235 & 0.160 & 0.238 \\
\hline 3 & Safety Assurance & 0.220 & 0.271 & 0.250 & 0.221 & 0.120 & 0.216 \\
\hline \multirow[t]{2}{*}{4} & Safety Promotion & 0.180 & 0.257 & 0.176 & 0.250 & 0.400 & 0.253 \\
\hline & Total & 1.000 & 1.000 & 1.000 & 1.000 & 1.000 & 1.000 \\
\hline
\end{tabular}

${ }^{1}$ Average of all inputs.

Note. A determination of the averages for each component. The final column, Marbles, reflects the average of averages for each component. The number 0.292, for example, means that $29.2 \%$ of the total of $100 \%$ is accounted for by Component 1 , Safety Policy and Objectives.

Each of the team members was asked to work independently, without collaboration with other team members; a collaboration activity was planned for later in the experiment. It was not necessary to be concerned about the total number of marbles that each member chose for each component because the average of the whole for each member would be computed, and the averages would then be used for comparison. This exercise produced the following results which represent the relative importance of each of the SMS components to the overall system (Table 3):

Interdependencies. The next objective was to determine the interdependencies of each component to the others. Determining the interdependencies is a cornerstone concept of IO. The following information was provided to the research team:

Okay here we go with round two, exercise 1. There will be four exercises in all for this round; this is the first.

The purpose of this and the other three exercises will be to try and determine how the four components of the SMS depend on one another. To illustrate, let's use a classic economic IO example. Let's say a particular sector of the economy has three sectors: Agriculture, Manufacturing, and Steel Production. Let's say that Agriculture produces 500 tons of wheat. Here's the matrix:

Agriculture Manufacturing Steel Production Output Agriculture 500 tons of wheat

So in the production of this wheat, how much of it is due to Manufacturing (for tractors and such)? And how much is due to Steel production? Let's assume that 40 tons is due to Manufacturing, and 10 tons is due to Steel Production. Then the matrix would look like this:

Agriculture Manufacturing Steel Production Output $\begin{array}{llll}\text { Agriculture } & 450 & 40 & 10\end{array}$ Tons of wheat

The output of 500 tons of wheat is the same, but it took some help from the other two sectors to get there.
So that's what we're trying to do with SMS today, to figure out the dependencies between the components. I've given you a spreadsheet that looks something like this

\section{SPO SRM SA SP Total

$292 \quad 292$

What I'm asking you to do is to look at the total number of marbles for Safety Policy and Objectives (SPO) (in this case 292-which is the average percentage derived from round one). I'm using three digits (292) to make it easier for you to spread.

The total reflects 292, and the number under the column "Safety Policies and Procedures" will start out at 292 but will diminish as you determine the number of marbles from the other components that help make up 292 for SPO. The total column should not change.

For example if you think that some of the Safety Policies and Procedures concern Safety Risk Management, then apply some of your marbles there. In the example below, we assume that 12 marbles should be pulled from Safety Risk Management and none from the other components. Here's how the matrix would look:

$\begin{array}{ccccc}S P O & \text { SRM } & \text { SA } & \text { SP } & \text { Total } \\ 280 & 12 & 0 & 0 & 292\end{array}$

Okay, are you ready to give it a go? Let's do it. Place your marbles in the attached spreadsheet.

Table 4

Interdependecies of SMS component 1 (SPO).

\begin{tabular}{lrrrrr}
\hline Component 1 & SPO & SRM & SA & SP & Total \\
\hline SPO & & & & & 292 \\
Member 1 & 117 & 85 & 65 & 25 & 292 \\
Member 2 & 60 & 140 & 10 & 82 & 292 \\
Member 3 & 122 & 80 & 40 & 50 & 292 \\
Member 4 & 132 & 20 & 60 & 80 & 292 \\
Member 5 & 67 & 100 & 50 & 75 & 292 \\
Total & 498 & 425 & 225 & 312 & \\
Average & 99.6 & 85 & 45 & 62.4 & 292 \\
\hline
\end{tabular}


Table 5

Table of interdependecies of all SMS components.

\begin{tabular}{lrrrrr}
\hline & SPO & SRM & SA & SP & Total \\
\hline $\begin{array}{l}\text { Interdependencies 1 (Safety Policy and } \\
\quad \text { Objectives) }\end{array}$ & 100 & 85 & 45 & 62 & 292 \\
$\begin{array}{l}\text { Interdependencies 2 (Safety Risk } \\
\quad \text { Management) }\end{array}$ & 46 & 115 & 51 & 26 & 238 \\
$\begin{array}{l}\text { Interdependencies 3 (Safety Assurance) } \\
\text { Interdependencies 4 (Safety Promotion) }\end{array}$ & 53 & 56 & 84 & 28 & 216 \\
\hline
\end{tabular}

Note. The interdependency of each component to the others is described by this table.

The first round of the interdependencies exercise produced the following results (Table 4):

The preceding exercise was repeated to determine the interdependencies for each of the remaining three components of SMS. The following results were determined (Table 5):

The next step was to meet in a face-to-face collaboration among the five SMEs and the team leader. Each of the interdependencies was discussed, and SMEs were allowed to change their original submissions, if they so desired. This meeting produced the following numbers:

$$
\begin{aligned}
& \text { SPO - 285 } \\
& \text { SRM - 265 } \\
& \text { SA - 222 } \\
& \text { SP - 228 }
\end{aligned}
$$

Vertical distribution. With the interdependency data established, it was now necessary to create the distribution of values relative to each component because most components have elements and processes. Each of these elements or processes has a discrete relationship to its component. For example, component SPO has five contributing elements:

- Management Commitment and Responsibility

- Safety Accountabilities

- Appointment of Key Safety Personnel

- Coordination of Emergency Response Planning

- SMS Documentation

To fully describe the component, it became necessary to determine what numerical role each of the elements played. To do this, a series of vertical distribution exercises were engaged. For example, the component SPO has a value of 285. But how does each of the five elements that make up the SPO component contribute to the total of 285? This was the question that the exercise needed to answer. The exercise was termed "Vertical Distribution" and was undertaken for each component. The following comprises the instructions to the team to accomplish this task:

Now it is time to take the new values and spread them vertically. To assist in this, I've attached spreadsheets

\begin{tabular}{|c|c|c|c|c|}
\hline & Maximum & Goal & Actual & \\
\hline Comp 1 - SPO - Element 1.1 Safety Policy & 59.1 & 44.0 & 33.4 & \\
\hline Element 1.2 Management & 54.0 & 40.2 & 30.5 & \\
\hline 1.3 Key Safety People & 39.0 & 29.0 & 22.0 & \\
\hline 1.4 Emergency Prep & 17.0 & 12.6 & 9.6 & \\
\hline 1.5 Documentation & 23.2 & 17.3 & 13.1 & \\
\hline Comp 2 - SRM - Element 2.1; Process 2.1.1 Sys Descr & 27.9 & 20.7 & 15.3 & \\
\hline Process 2.1.2 Identify Hazards & 46.0 & 34.2 & 26.0 & \\
\hline Element 2.2; Process 2.2.1Analyze Safety Risk & 23.5 & 21.2 & 16.1 & \\
\hline 2.2.2 Assess Safety Risk & 32.7 & 24.3 & 18.5 & \\
\hline 2.2.3 Control/Mtgate Risk & 42.5 & 31.6 & 24.0 & \\
\hline Comp 3 - SA - Element 3.1; Process 3.1.1 Continuous Monitoring & 10.3 & 3.0 & 6.1 & \\
\hline 3.1.2 Internal Audits & 9.3 & 6.9 & 5.2 & \\
\hline 3.1.3 Internal Evaluation & 7.9 & 5.9 & 4.5 & \\
\hline 3.1.4 External Audits & 14.9 & 11.1 & 8.4 & \\
\hline 3.1.5 Investigation & 16.5 & 12.3 & 9.4 & \\
\hline 3.1.6 Employee Reporting & 19.0 & 14.1 & 10.7 & \\
\hline 3.1.7 Analysis of Data & 14.3 & 10.6 & 8.1 & \\
\hline 3.1.8 System Assessment & 3.5 & 6.3 & 4.8 & \\
\hline Element 3.2; Management of Change & 19.6 & 14.6 & 11.1 & \\
\hline Element 3.3; Process 3.3.1 Preventive/Corrective Action & 16.9 & 12.6 & 9.6 & \\
\hline 3.3.2 Management Review & 11.6 & 3.6 & 6.5 & \\
\hline Comp 4 - SP- Element 4.1; Process 4.1.1 Personnel Competence & 33.9 & 23.9 & 22.0 & \\
\hline 4.1.2 Training & 43.2 & 32.1 & 24.4 & \\
\hline \multirow[t]{2}{*}{ Element 4.2 Communication \& Awareness } & 70.3 & 52.7 & 40.1 & \\
\hline & 672.0 & 500.0 & 380.0 & Sum of $x$ \\
\hline
\end{tabular}
with your name in the file.

Table 6

An application of the matrix relative to a hypothetical survey.

Note. The relationship of each of the 24 discrete values is shown in this table. The Goal was 500 , but the Actual achievement was 380 compared to a Maximum attainable of 672 
You'll notice, for example, that Safety Policy and Objectives has 285 marbles. It also has five items that make up the component. Your task, then, is to distribute the 285 marbles in the way you see fit to each of the five items in the column under your name. The spreadsheet will total the component as you input the values. Your total should not exceed 285 marbles for Safety Policy and Objectives. Repeat this for the other three components; each has its own number of marbles (Safety Risk Management - 265; Safety Assurance - 222, and Safety Promotion - 228). Once you've done this, return the file to me.

Within the next couple of weeks, I'll get us together for a couple of hours so that I can go into detail about what we did. This will also give you the chance to discuss, reconsider, or change any input you've made. Once we've completed this collaboration, I plan to subject the matrix to input-output mathematics. I'll keep you informed as we go.

This exercise produced the vertical distribution data shown in Table 9, Appendix A. The next step was to create a matrix that captured all of the relational data. Since there were 24 discrete categories ( 7 elements and 17 processes), a $24 \times 24$ matrix was calculated. This was accomplished by determining the percentage of each element or process within a given component in both the $\mathrm{x}$ and $\mathrm{y}$ axes. This process produced the $24 \times 24$ matrix shown in Appendix A, Tables 9 and 10 .

With this information, the team was now ready to calculate the IO Matrix.

\section{Results}

\section{Calculating the IO Matrix for SMS}

The team used a closed input-output model since all the point values were to be distributed among the 24 SMS components. In this model, we solved the system $x=A x$, where $A$ is the $24 \times 24$ input-output matrix, and $x$ is the $24 \times 1$ production matrix.

$A=\left[a_{i j}\right](\mathrm{i}, \mathrm{j}=1,2 \ldots 24)$, where entry $a_{i j}$ of the matrix represents the point value of component $i$ for one point value of component $\mathrm{j}$.

$x=\left[x_{i}\right](\mathrm{i}=1,2 \ldots 24)$ where $x_{i}$ represents the point value of component $\mathrm{i}$.

The input-output matrix $A$ was generated by normalizing the matrix from Appendix A, Tables 9 and 10, such that the sum of each of the columns of matrix $A$ equals 1 .

Table 7

An application of the matrix relative to a hypothetical audit.

\begin{tabular}{|c|c|c|c|}
\hline & Maximum & Actual & \\
\hline Comp 1 - SPO - Element 1.1 Safety Policy & 44.0 & 30.8 & \\
\hline Element 1.2 Management & 40.2 & 28.1 & \\
\hline 1.3 Key Safety People & 29.0 & 20.3 & \\
\hline 1.4 Emergency Prep & 12.6 & 8.9 & \\
\hline 1.5 Documentation & 17.3 & 12.1 & \\
\hline Comp 2 - SRM - Element 2.1; Process 2.1.1 Sys Descr & 20.7 & 14.5 & \\
\hline Process 2.1.2 Identify Hazards & 34.2 & 23.9 & \\
\hline Element 2.2; Process 2.2.1 Analyze Safety Risk & 21.2 & 14.9 & \\
\hline 2.2.2 Assess Safety Risk & 24.3 & 17.0 & \\
\hline 2.2.3 Control/Mtgate Risk & 31.6 & 22.1 & \\
\hline Comp 3 - SA - Element 3.1; Process 3.1.1 Continuous Monitoring & 8.0 & 5.6 & \\
\hline 3.1.2 Internal Audits & 6.9 & 4.8 & \\
\hline 3.1.3 Internal Evaluation & 5.9 & 4.1 & \\
\hline 3.1.4 External Audits & 11.1 & 7.8 & \\
\hline 3.1.5 Investigation & 12.3 & 8.6 & \\
\hline 3.1.6 Employee Reporting & 14.1 & 9.9 & \\
\hline 3.1.7 Analysis of Data & 10.6 & 7.4 & \\
\hline 3.1.8 System Assessment & 6.3 & 4.4 & \\
\hline Element 3.2; Management of Change & 14.6 & 10.2 & \\
\hline Element 3.3; Process 3.3.1 Preventive/Corrective Action & 12.6 & 8.8 & \\
\hline 3.3.2 Management Review & 8.6 & 6.0 & \\
\hline Comp 4 - SP - Element 4.1; Process 4.1.1 Personnel Competence & 28.9 & 20.3 & \\
\hline 4.1.2 Training & 32.1 & 22.5 & \\
\hline \multirow[t]{2}{*}{ Element 4.2 Communication \& Awareness } & 52.7 & 36.9 & \\
\hline & 500.0 & 350.0 & Sum of $x$ \\
\hline
\end{tabular}

Note. An audit was used to populate this matrix. The maximum score available was 500 . The person administering the audit determined that the organization scored 350. 
Table 8

The impact of changing a single value.

\begin{tabular}{|c|c|c|c|c|}
\hline & Ideal & Actual & What if? & \\
\hline Comp 1 - SPO - Element 1.1 Safety Policy & 44.0 & 30.8 & 37.4 & \\
\hline Element 1.2 Management & 40.2 & 28.1 & 34.2 & \\
\hline 1.3 Key Safety People & 29.0 & 20.3 & 24.7 & \\
\hline 1.4 Emergency Prep & 12.6 & 8.9 & 10.8 & \\
\hline 1.5 Documentation & 17.3 & 12.1 & 14.7 & \\
\hline Comp 2 - SRM - Element 2.1; Process 2.1.1 Sys Descr & 20.7 & 14.5 & 17.6 & \\
\hline Process 2.1.2 Identify Hazards & 34.2 & 23.9 & 29.1 & \\
\hline Element 2.2; Process 2.2.1 Analyze Safety Risk & 21.2 & 14.9 & 18.1 & \\
\hline 2.2.2 Assess Safety Risk & 24.3 & 17.0 & 20.7 & \\
\hline 2.2.3 Control/Mtgate Risk & 31.6 & 22.1 & 26.9 & \\
\hline Comp 3 - SA - Element 3.1; Process 3.1.1 Continuous Monitoring & 8.0 & 5.6 & 6.8 & \\
\hline 3.1.2 Internal Audits & 6.9 & 4.8 & 5.9 & \\
\hline 3.1.3 Internal Evaluation & 5.9 & 4.1 & 5.0 & \\
\hline 3.1.4 External Audits & 11.1 & 7.8 & 9.4 & \\
\hline 3.1.5 Investigation & 12.3 & 8.6 & 10.5 & \\
\hline 3.1.6 Employee Reporting & 14.1 & 9.9 & 12.0 & \\
\hline 3.1.7 Analysis of Data & 10.6 & 7.4 & 9.0 & \\
\hline 3.1.8 System Assessment & 6.3 & 4.4 & 5.4 & \\
\hline Elernent 3.2; Management of Change & 14.6 & 10.2 & 12.4 & \\
\hline Element 3.3; Process 3.3.1 Preventive/Corrective Action & 12.6 & 8.8 & 10.7 & \\
\hline 3.3.2 Management Review & 8.6 & 6.0 & 7.3 & \\
\hline Comp 4 - SP - Element 4.1; Process 4.1.1 Personnel Competence & 28.9 & 20.3 & 24.6 & \\
\hline 4.1.2 Training & 32.1 & 22.5 & 27.3 & \\
\hline \multirow[t]{2}{*}{ Element 4.2 Communication \& Awareness } & 52.7 & 36.9 & 44.8 & \\
\hline & 500.0 & 350.0 & 425.4 & Sum of $x$ \\
\hline
\end{tabular}

Note. What if analysis: testing the impact of changing one variable, 3.1.6, Employee Reporting, from 9.9 to 12.

To solve the closed system $x=A x$, we solved the system of equations $(I-A)^{-1} x=0$, where $I$ is the $24 \times 24$ identity matrix, and $O$ is the $24 \times 1$ zero matrix.

This system does not have a unique solution. But a solution, $x$, can be found in terms of a parameter. That is, if the total point values (sum of $x, \sum_{i=1}^{24} x_{i}$ ) is known, then the distribution of the point values for the 24 components $\left(x_{i}^{\prime} s\right)$ can be computed (Table 6). Or, if the point value for one of the components, say $x_{i}$, is known, then the point values for the other 23 components, $x_{j}(j \neq i)$ can be computed (Table 7). These two scenarios are discussed further with examples described in the sections that follow.

\section{The Resulting SMS IO Matrix}

The SMS matrix that resulted from this experiment may be a powerful management tool. The sum of $\mathrm{x}$, for example, can be data from any source. In the case of the example provided, the data source is a hypothetical SMS questionnaire that had as a goal the score of 500; that number is reflected at the bottom of the "Goal" column. The maximum attainable value is 672 (seven points each for 96 questions). Once the hypothetical survey was administered, the composite score (the total of the response values) was 380 (sum of x). Note the distribution of values in the Actual column. One can compare the desired values in the Goal column to the values in the Actual column to see where the greater deficiencies lie
(Table 6). Taken one step further, since the maximum score available is 672 and each of the 24 discrete elements has a value related to 672 , one can not only compare the Actual to the Goal but also to the Maximum available.

It is important to note that a variety of different inputs can be used to access the IO matrix. For example, assume that the input device is an audit checklist completed by a safety professional during a periodical SMS audit. This audit can be empirically scored by the person accomplishing the audit. It is a 10 question audit with each question counting 10 points for a maximum of 500 . For this audit, the safety professional determined that the organization scored 350. Table 7 depicts how the IO matrix would look.

If examined in isolation, the SMS IO table seems meaningless. However, viewed against a norm or as a trend over several years, the results will be very illuminating about what is occurring inside the SMS. For example, an SMS practitioner could administer the survey or audit yearly to detect areas of safety erosion or gain and to measure the overall health of the SMS as perceived by the members of the organization.

\section{What If}

Another important artifact of the SMS IO matrix is the capability of the matrix to determine what will happen if a point value is changed. Given that SMS practitioners are often 
resource limited, the matrix provides a scientific method for determining what investment might produce the biggest rewards by assessing how one changed component affects the overall SMS. For example, what if it was desired to know the impact of changing a single value, say 3.1.6, Employee Reporting, from the Actual value of 10.7 to 12 ? Observe in the "What if" column the effect of this change (Table 8). All of the values changed upward as did the total (sum of $\mathrm{x}$ ). This is because of the interrelatedness of each of the 24 discrete values to one another. If management action is taken to improve one area, all other areas are affected. Clearly, Employee Reporting is not an isolated and independent variable but is affected by and affects all of the others.

\section{Discussion}

\section{Limitations of the Research}

The matrix is highly sensitive to the original input data that define the interrelationships between the components. If these relationships are incorrect, then the entire matrix will likely be incorrect. Referring again to Table 10, note that the origin of the relationships is described. The average of each member's inputs for each component is shown in the lower part of the chart. The averages are then averaged as shown under the Marbles column. As a specific example, note that the average of the averages for the five members for Safety Policy and Objectives is .292. But a close examination shows a fairly wide variability in the inputs from the various members, ranging from .229 to .340. It is worse in Safety Risk Management, ranging from .160 to .294 . With such wide variability, the accuracy of the eventual matrix can be questioned.

This entire SMS IO experiment, then, can be viewed as a proof of concept. For the SMS IO to become a useful tool, the variability among the Subject Matter Experts should be reduced to an acceptable range. This can be done by assembling a group of 15-20 SMS Subject Matter Experts from around the country, standardizing them to the process, re-creating the data, and re-accomplishing all of the steps which should result in a matrix that shows more accurately the interrelationships between the SMS components, elements, and processes, and is both reliable and valid.

\section{References}

Carey, B. (2015, January 7). FAA releases final rule requiring aircraft safety systems. AIN Online. Retrieved from http://www.ainonline. com/aviation-news/air-transport/2015-01-07/faa-releases-final-rulerequiring-airline-safety-systems

Dietzenbacher, E., Lenzen, M., Los, B., Guan, D., Lahr, M., Sancho, F., \& Cuihong, Y. (2013). Input-output analysis: The next 25 years. Economics Systems Research, 25(4), 369-389.

Federal Aviation Administration (FAA). (2015). Safety Management Systems for aviation service providers (AC 120-92B). Retrieved from http://www. faa.gov/documentLibrary/media/Advisory_Circular/AC_120-92B.pdf

Federal Aviation Administration. (2015, January 8). Safety Management Systems for domestic, flag, and supplemental operations certificate holders (80 Fed. Reg. 5).

George, K. W. (2015). Economic interrelationships and impacts of the aviation/aerospace industries in the state of Florida using input-output analysis (Unpublished doctoral dissertation). Embry-Riddle Aeronautical University, Daytona Beach, Florida.

Isard, W., Azis, M., Drennan, M., Miller, R., Salzman, S., \& Thorbecke, E. (1998b). Regional and interregional input-output analysis, chapter 3. Brookfield, VT: Ashgate.

International Civil Aviation Organization (ICAO). (2013). Safety Management Manual (SMM), (Doc 9859 AN/474), . Montréal, Canada: ICAO.

Leontief, W. (1986). Input-output economic. New York, NY: Oxford University Press.

Miller, R., \& Blair, P. (2009). Input-output analysis foundations and extensions. Cambridge, NY: Cambridge University Press.

Stolzer, A., Halford, C. \& Goglia, J. (2015). Safety Management Systems in aviation. (2nd ed.). Burlington, VT: Ashgate Publications. 


\section{Appendix A}

Table 9

Determining the vertical distribution values.

\begin{tabular}{clcc}
\hline Component 1 Safety Policy and Objectives & Vert. Dist. & $\%$ \\
\hline 1 & Element 1.1 Safety Policy & 87.6 & 0.307 \\
2 & Element 1.2 Management Commitment \& Safety Accountabilities & 80 & 0.281 \\
3 & Element 1.3 Key safety personnel & 57.8 & 0.203 \\
4 & Element 1.4 Emergency Preparedness \& Response & 25.2 & 0.088 \\
5 & Element 1.5 SMS Documentation \& Records & 34.4 & 0.121
\end{tabular}

Componet 2. Safety Risk Management

Element 2.1 Hazard Identification \& Analysis

$6 \quad$ Process 2.1.1. System Description \& Task Analysis

Process 2.1.2. Identify Hazards

$\begin{array}{ccc} & 41.6 & 0.157 \\ & 68.6 & 0.259 \\ & 42.6 & 0.161 \\ & 48.8 & 0.184 \\ \text { Total } & 63.4 & 0.239\end{array}$

Element 2.2 Safety Risk Assessment and mitigation

8 Process 2.2.1. Analyze Safety Risk

Process 2.2.2. Assess Safety Risk

10 Process 2.2.3. Control/Mitigate Safety Risk

Componet 3. Safety Assurance

Total 265

Element 3.1 Safety performance monitoring and measurement

Process 3.1.1 Continuous Monitoring

Process 3.1.2. Internal Audits by Operational Departments

Process 3.1.3. Internal Valuation

Process 3.1.4. External Auditing of SMS

$13.8 \quad 0.062$

$11.8 \quad 0.053$

Process 3.1.5. Investigation

$22.2 \quad 0.100$

Process 3.1.6. Employee Reporting \& Feedback System

24.6

0.111

Process 3.1.7. Analysis of Data

$28.2 \quad 0.127$

Process 3.1.8. System Assessment

$\begin{array}{ll}21.2 & 0.095\end{array}$

$12.6 \quad 0.057$

Element 3.2 Management of change

Element 3.3. Continuous improvement

$29.2 \quad 0.132$

Process 3.3.1. Preventative/Corrective Action

$25.2 \quad 0.114$

21 Process 3.3.2. Management Review

Component 4. Safety Promotion

Total 222

Element 4.1 Competencies and Training

22 Process 4.1.1. Personnel Expectations (Competence)

Process 4.1.2. Training

Element 4.2. Communication \& Awareness

$\begin{array}{cc}58 & 0.254 \\ 64.4 & 0.282 \\ 105.6 & 0.463\end{array}$

Total 228

Note: The inputs from each team member were averaged to produce the values under the Marbles column. The column on the far right is used to list the percentage of each Element or Process relative to its respective Component. 
Table 10

Calculating the $24 \times 24$ matrix (1st half).

\begin{tabular}{|c|c|c|c|c|c|c|c|c|c|c|c|c|c|c|}
\hline & & & 1 & 2 & 3 & 4 & 5 & 6 & 7 & 8 & 9 & 10 & 11 & 12 \\
\hline & & & 112.8 & & & & & 69 & & & & & 50 & \\
\hline & & & 34.67 & 31.66 & 22.88 & 9.97 & 13.62 & 10.83 & 17.86 & 11.09 & 12.71 & 16.51 & 3.60 & 3.11 \\
\hline & & Percentage & 1.1 & 1.2 & 1.3 & 1.4 & 1.5 & 2.1 .1 & 2.1 .2 & 2.2 .1 & 2.2 .2 & 2.2 .3 & 3.1 .1 & 3.1 .2 \\
\hline 1 & 1.1 & 0.3074 & 10.66 & 9.73 & 7.03 & 3.07 & 4.18 & 3.33 & 5.49 & 3.41 & 3.91 & 5.07 & 1.11 & 0.96 \\
\hline 2 & 1.2 & 0.2807 & 9.73 & 8.89 & 6.42 & 2.80 & 3.82 & 3.04 & 5.01 & 3.11 & 3.57 & 4.63 & 1.01 & 0.87 \\
\hline 3 & 1.3 & 0.2028 & 7.03 & 6.42 & 4.64 & 2.02 & 2.76 & 2.20 & 3.62 & 2.25 & 2.58 & 3.35 & 0.73 & 0.63 \\
\hline 4 & 1.4 & 0.0884 & 3.07 & 2.80 & 2.02 & 0.88 & 1.20 & 0.96 & 1.58 & 0.98 & 1.12 & 1.46 & 0.32 & 0.27 \\
\hline \multirow[t]{3}{*}{5} & 1.5 & 0.1207 & 4.18 & 3.82 & 2.76 & 1.20 & 1.64 & 1.31 & 2.16 & 1.34 & 1.53 & 1.99 & 0.43 & 0.38 \\
\hline & & & 64 & & & & & 94 & & & & & & 63 \\
\hline & & & 19.67 & 17.96 & 12.98 & 5.66 & 7.72 & 14.76 & 24.33 & 15.11 & 17.31 & 22.49 & 4.54 & 3.92 \\
\hline 6 & 2.1 .1 & 0.1570 & 3.09 & 2.82 & 2.04 & 0.89 & 1.21 & 2.32 & 3.82 & 2.37 & 2.72 & 3.53 & 0.71 & 0.61 \\
\hline 7 & 2.1 .2 & 0.2589 & 5.09 & 4.65 & 3.36 & 1.46 & 2.00 & 3.82 & 6.30 & 3.91 & 4.48 & 5.82 & 1.18 & 1.01 \\
\hline 8 & 2.2 .1 & 0.1608 & 3.16 & 2.89 & 2.09 & 0.91 & 1.24 & 2.37 & 3.91 & 2.43 & 2.78 & 3.62 & 0.73 & 0.63 \\
\hline 9 & 2.2 .2 & 0.1842 & 3.62 & 3.31 & 2.39 & 1.04 & 1.42 & 2.72 & 4.48 & 2.78 & 3.19 & 4.14 & 0.84 & 0.72 \\
\hline \multirow[t]{3}{*}{10} & 2.2 .3 & 0.2392 & 4.71 & 4.30 & 3.11 & 1.35 & 1.85 & 3.53 & 5.82 & 3.62 & 4.14 & 5.38 & 1.09 & 0.94 \\
\hline & & & 49 & & & & & 61.6 & & & & & & 74.6 \\
\hline & & & 14.94 & 13.64 & 9.86 & 4.30 & 5.87 & 9.67 & 15.95 & 9.90 & 11.34 & 14.74 & 5.38 & 4.64 \\
\hline 11 & 3.1 .1 & 0.0721 & 1.08 & 0.98 & 0.71 & 0.31 & 0.42 & 0.70 & 1.15 & 0.71 & 0.82 & 1.06 & 0.39 & 0.33 \\
\hline 12 & 3.1 .2 & 0.0622 & 0.93 & 0.85 & 0.61 & 0.27 & 0.36 & 0.60 & 0.99 & 0.62 & 0.71 & 0.92 & 0.33 & 0.29 \\
\hline 13 & 3.1 .3 & 0.0532 & 0.79 & 0.73 & 0.52 & 0.23 & 0.31 & 0.51 & 0.85 & 0.53 & 0.60 & 0.78 & 0.29 & 0.25 \\
\hline 14 & 3.1 .4 & 0.1000 & 1.49 & 1.36 & 0.99 & 0.43 & 0.59 & 0.97 & 1.59 & 0.99 & 1.13 & 1.47 & 0.54 & 0.46 \\
\hline 15 & 3.1 .5 & 0.1108 & 1.66 & 1.51 & 1.09 & 0.48 & 0.65 & 1.07 & 1.77 & 1.10 & 1.26 & 1.63 & 0.60 & 0.51 \\
\hline 16 & 3.1 .6 & 0.1270 & 1.90 & 1.73 & 1.25 & 0.55 & 0.75 & 1.23 & 2.03 & 1.26 & 1.44 & 1.87 & 0.68 & 0.59 \\
\hline 17 & 3.1 .7 & 0.0955 & 1.43 & 1.30 & 0.94 & 0.41 & 0.56 & 0.92 & 1.52 & 0.95 & 1.08 & 1.41 & 0.51 & 0.44 \\
\hline 18 & 3.1 .8 & 0.0568 & 0.85 & 0.77 & 0.56 & 0.24 & 0.33 & 0.55 & 0.91 & 0.56 & 0.64 & 0.84 & 0.31 & 0.26 \\
\hline 19 & 3.2 & 0.1315 & 1.96 & 1.79 & 1.30 & 0.57 & 0.77 & 1.27 & 2.10 & 1.30 & 1.49 & 1.94 & 0.71 & 0.61 \\
\hline 20 & 3.3 .1 & 0.1135 & 1.70 & 1.55 & 1.12 & 0.49 & 0.67 & 1.10 & 1.81 & 1.12 & 1.29 & 1.67 & 0.61 & 0.53 \\
\hline \multirow[t]{3}{*}{21} & 3.3 .2 & 0.0775 & 1.16 & 1.06 & 0.76 & 0.33 & 0.45 & 0.75 & 1.24 & 0.77 & 0.88 & 1.14 & 0.42 & 0.36 \\
\hline & & & 54 & & & & & 43.4 & & & & & & 33.4 \\
\hline & & & 16.47 & 15.05 & 10.87 & 4.74 & 6.47 & 6.81 & 11.23 & 6.98 & 7.99 & 10.38 & 2.41 & 2.08 \\
\hline 22 & 4.1.1 & 0.2544 & 4.19 & 3.83 & 2.77 & 1.21 & 1.65 & 1.73 & 2.86 & 1.77 & 2.03 & 2.64 & 0.61 & 0.53 \\
\hline 23 & 4.1.2 & 0.2825 & 4.65 & 4.25 & 3.07 & 1.34 & 1.83 & 1.92 & 3.17 & 1.97 & 2.26 & 2.93 & 0.68 & 0.59 \\
\hline 24 & 4.2 & 0.4632 & 7.63 & 6.97 & 5.03 & 2.20 & 3.00 & 3.16 & 5.20 & 3.23 & 3.70 & 4.81 & 1.11 & 0.96 \\
\hline
\end{tabular}


Table 11

Calculating the $24 \times 24$ matrix ( 2 nd half).

\begin{tabular}{|c|c|c|c|c|c|c|c|c|c|c|c|c|c|c|}
\hline & & & 13 & 14 & 15 & 16 & 17 & 18 & 19 & 20 & 21 & 22 & 23 & 24 \\
\hline & & & & & & & & & & & & 53.4 & & \\
\hline & & & 2.66 & 5.00 & 5.54 & 6.35 & 4.77 & 2.84 & 6.58 & 5.68 & 3.87 & 13.58 & 15.08 & 24.73 \\
\hline & & Percentage & 3.1 .3 & 3.1 .4 & 3.1 .5 & 3.1 .6 & 3.1 .7 & 3.1 .8 & 3.2 & 3.3 .1 & 3.3 .2 & 4.1 .1 & 4.1 .2 & 4.2 \\
\hline 1 & 1.1 & 0.3074 & 0.82 & 1.54 & 1.70 & 1.95 & 1.47 & 0.87 & 2.02 & 1.74 & 1.19 & 4.18 & 4.64 & 7.60 \\
\hline 2 & 1.2 & 0.2807 & 0.75 & 1.40 & 1.56 & 1.78 & 1.34 & 0.80 & 1.85 & 1.59 & 1.09 & 3.81 & 4.23 & 6.94 \\
\hline 3 & 1.3 & 0.2028 & 0.54 & 1.01 & 1.12 & 1.29 & 0.97 & 0.58 & 1.33 & 1.15 & 0.79 & 2.75 & 3.06 & 5.02 \\
\hline 4 & 1.4 & 0.0884 & 0.23 & 0.44 & 0.49 & 0.56 & 0.42 & 0.25 & 0.58 & 0.50 & 0.34 & 1.20 & 1.33 & 2.19 \\
\hline \multirow[t]{3}{*}{5} & 1.5 & 0.1207 & 0.32 & 0.60 & 0.67 & 0.77 & 0.58 & 0.34 & 0.79 & 0.69 & 0.47 & 1.64 & 1.82 & 2.99 \\
\hline & & & & & & & & & & & & 43.8 & & \\
\hline & & & 3.35 & 6.30 & 6.98 & 8.00 & 6.02 & 3.58 & 8.29 & 7.15 & 4.88 & 11.14 & 12.37 & 20.29 \\
\hline 6 & 2.1 .1 & 0.1570 & 0.53 & 0.99 & 1.10 & 1.26 & 0.94 & 0.56 & 1.30 & 1.12 & 0.77 & 1.75 & 1.94 & 3.18 \\
\hline 7 & 2.1 .2 & 0.2589 & 0.87 & 1.63 & 1.81 & 2.07 & 1.56 & 0.93 & 2.15 & 1.85 & 1.26 & 2.88 & 3.20 & 5.25 \\
\hline 8 & 2.2 .1 & 0.1608 & 0.54 & 1.01 & 1.12 & 1.29 & 0.97 & 0.57 & 1.33 & 1.15 & 0.78 & 1.79 & 1.99 & 3.26 \\
\hline 9 & 2.2 .2 & 0.1842 & 0.62 & 1.16 & 1.29 & 1.47 & 1.11 & 0.66 & 1.53 & 1.32 & 0.90 & 2.05 & 2.28 & 3.74 \\
\hline \multirow[t]{3}{*}{10} & 2.2 .3 & 0.2392 & 0.80 & 1.51 & 1.67 & 1.91 & 1.44 & 0.86 & 1.98 & 1.71 & 1.17 & 2.67 & 2.96 & 4.85 \\
\hline & & & & & & & & & & & & 37.6 & & \\
\hline & & & 3.97 & 7.46 & 8.27 & 9.48 & 7.12 & 4.23 & 9.81 & 8.47 & 5.78 & 9.56 & 10.62 & 17.41 \\
\hline 11 & 3.1 .1 & 0.0721 & 0.29 & 0.54 & 0.60 & 0.68 & 0.51 & 0.31 & 0.71 & 0.61 & 0.42 & 0.69 & 0.77 & 1.26 \\
\hline 12 & 3.1 .2 & 0.0622 & 0.25 & 0.46 & 0.51 & 0.59 & 0.44 & 0.26 & 0.61 & 0.53 & 0.36 & 0.59 & 0.66 & 1.08 \\
\hline 13 & 3.1 .3 & 0.0532 & 0.21 & 0.40 & 0.44 & 0.50 & 0.38 & 0.23 & 0.52 & 0.45 & 0.31 & 0.51 & 0.56 & 0.93 \\
\hline 14 & 3.1 .4 & 0.1000 & 0.40 & 0.75 & 0.83 & 0.95 & 0.71 & 0.42 & 0.98 & 0.85 & 0.58 & 0.96 & 1.06 & 1.74 \\
\hline 15 & 3.1 .5 & 0.1108 & 0.44 & 0.83 & 0.92 & 1.05 & 0.79 & 0.47 & 1.09 & 0.94 & 0.64 & 1.06 & 1.18 & 1.93 \\
\hline 16 & 3.1 .6 & 0.1270 & 0.50 & 0.95 & 1.05 & 1.20 & 0.90 & 0.54 & 1.25 & 1.08 & 0.73 & 1.22 & 1.35 & 2.21 \\
\hline 17 & 3.1 .7 & 0.0955 & 0.38 & 0.71 & 0.79 & 0.90 & 0.68 & 0.40 & 0.94 & 0.81 & 0.55 & 0.91 & 1.01 & 1.66 \\
\hline 18 & 3.1 .8 & 0.0568 & 0.23 & 0.42 & 0.47 & 0.54 & 0.40 & 0.24 & 0.56 & 0.48 & 0.33 & 0.54 & 0.60 & 0.99 \\
\hline 19 & 3.2 & 0.1315 & 0.52 & 0.98 & 1.09 & 1.25 & 0.94 & 0.56 & 1.29 & 1.11 & 0.76 & 1.26 & 1.40 & 2.29 \\
\hline 20 & 3.3 .1 & 0.1135 & 0.45 & 0.85 & 0.94 & 1.08 & 0.81 & 0.48 & 1.11 & 0.96 & 0.66 & 1.09 & 1.21 & 1.98 \\
\hline \multirow[t]{3}{*}{21} & 3.3 .2 & 0.0775 & 0.31 & 0.58 & 0.64 & 0.73 & 0.55 & 0.33 & 0.76 & 0.66 & 0.45 & 0.74 & 0.82 & 1.35 \\
\hline & & & & & & & & & & & & 97.2 & & \\
\hline & & & 1.78 & 3.34 & 4.81 & 4.24 & 3.19 & 1.90 & 4.39 & 3.79 & 2.59 & 24.73 & 27.45 & 45.02 \\
\hline 22 & 4.1.1 & 0.2544 & 0.45 & 0.85 & 1.22 & 1.08 & 0.81 & 0.48 & 1.12 & 0.96 & 0.66 & 6.29 & 6.98 & 11.45 \\
\hline 23 & 4.1 .2 & 0.2825 & 0.50 & 0.94 & 1.36 & 1.20 & 0.90 & 0.54 & 1.24 & 1.07 & 0.73 & 6.98 & 7.75 & 12.72 \\
\hline 24 & 4.2 & 0.4632 & 0.82 & 1.55 & 2.23 & 1.97 & 1.48 & 0.88 & 2.03 & 1.76 & 1.20 & 11.45 & 12.72 & 20.85 \\
\hline
\end{tabular}

